\title{
EXPERT-LIKE USE OF HEDGES AND BOOSTERS IN RESEARCH ARTICLES WRITTEN BY POLISH AND ENGLISH NATIVE-SPEAKER WRITERS
}

\author{
KATARZYNA HRYNIUK \\ University of Warsaw, Poland \\ k.hryniuk@uw.edu.pl
}

\begin{abstract}
The present study compares the use of main interpersonal metadiscourse markers - hedges and boosters - in a corpus of 40 research articles from the area of applied linguistics, written in English by native speakers and Polish writers. Used as communicative strategies, these words and expressions increase (boosters) or reduce (hedges) the force of arguments. In order to gain an in-depth insight and to achieve greater precision, in the analysis the author utilizes a concordance tool WordSmith 6.0 (Scott 2012). The results point to important discrepancies in the usage of these text features by authors representing different native languages and cultures. The study has important implications for developing competence in writing for publication in English as a Foreign Language.
\end{abstract}

Keywords: booster, corpus, hedge, metadiscourse, research article, writing for publication

\section{Introduction}

Gaining expertise in writing for publishing is presently increasingly important for academics in all disciplines, since publications in highly rated international journals have a great impact not only on knowledge construction through the process of writing, which is of primary importance, but also on their basis, universities are funded and scholars are evaluated. In Poland as well, the current academic evaluation system requires publication in English as a Foreign Language (EFL), also called English as an Additional Language (EAL) in this context, in prestigious international journals, where Anglo-American conventions prevail. At the same time, previous research shows that writers from other than Anglo-American cultural regions face many challenges when writing for publication in English because of distinct conventions that they follow, which are shaped by different literacy traditions.

Before discussing the issue of writing for publishing in EAL and the use of metadiscourse, first two concepts need to be distinguished, namely, secondlanguage proficiency for general language use and academic writing expertise (Cumming 1989), because they are often understood as equivalent. Certainly, advanced foreign language proficiency is a prerequisite for successful writing in EAL. As Cumming (1989) claims, it has an additive value, because greater or 
lesser level of it influences the quality of the text, but it is not sufficient. Expertise in academic writing requires also being able to engage in a highly complex composing process and this ability is attained with great effort in any language. As Weigle (2005) states, it is only rarely achieved even in the first language.

Academic writing, from socio-constructivist point of view, is a socially and culturally situated activity. Hence, expertise in writing for publishing develops through a writer's socialization into academic discourse community which shares a set of values and cultural preferences as to what 'good' writing should be like (e.g., Duff 2007, 2010; Flowerdew 2013; Hyland 2009). Expert writers, in order to complete the complex task of writing, must use a number of appropriate strategies and areas of knowledge, such as: topic and language knowledge, genre knowledge, audience knowledge, task schemas, and metacognition, which is "higher order thinking involving active management of the cognitive processes engaged in complex tasks" (Weigle 2005: 135).

Weigle (2005) makes a distinction between the engagement in cognitive activities by unskilled and skilled academic writers. As she claims, for experts writing is not less effortful than for novice writers. However, the main differences between them are that not only do skilled writers attend to conventions and orthography in writing, but also they make appropriate choices of syntactic structures and words to convey their messages, and they simultaneously monitor and evaluate their choices, bearing in mind a representation of a reader. They try to predict what will be persuasive for the audience, which rhetorical devices will be the most convincing, and how the readers will respond. They consider the readers' background and expectations. As Weigle (2005: 132) writes, "skilled writers are able to attend to a wider variety of considerations simultaneously, to use their resources flexibly in solving rhetorical and content problems, and to adjust their message to meet the needs of their audience." For novice EAL writers, on the other hand, the task of writing for publishing may be much more challenging, because they often lack appropriate knowledge of the conventions of writing or genre knowledge, and by imitating their native language ways of expression, they make inappropriate choices of metadiscourse. They frequently have worse awareness of the rhetorical effect that specific language resources can have on readers. Therefore, raising awareness of these language items use, especially among second language writers through corpus-based Data Driven Learning (DDL) (Johns 1991), as it is the case in the study carried out in this paper, can facilitate improvement in their writing.

Before outlining previous research results and describing the study carried out for the purposes of the present paper, the following terms need to be clarified: metadiscourse, and hedges and boosters (i.e., epistemic markers), belonging to the group of interpersonal metadiscourse markers, because they are the focus of the analysis. The most extensive work on metadiscourse, including a chapter discussing the definition of this term, is Hyland's (2005a) book published under this title. As the author writes, the term metadiscourse was coined by Zellig Harris 
in 1959 and it was introduced into the applied linguistics vocabulary in the 1980s (Hyland 2005a). In essence, as Hyland (2005a: 16) writes, "'metadiscourse' is an umbrella term, used to include an apparently heterogenous array of cohesive and interpersonal features which help relate a text to its context." It can be defined simply as "discourse about discourse." It is considered as a fuzzy term which encompasses a wide collection of language items used to describe both the organization of discourse and the ways in which we relate to our listeners or readers. The adjective 'fuzzy' here means that the concept lacks clear-cut boundaries. In other words, sometimes it is hard to make a precise distinction between what is and what is not metadiscourse (Ädel 2006). Although this does not eliminate the fuzziness of the term, in a wider sense, as applied linguists, composition theorists, and rhetoricians agree, metadiscourse refers to "the various linguistic tokens employed to guide or direct a reader through a text so both the text and the writer's stance is understood" (Hyland 2005a: 18). Hyland (2005a: 37) finally arrives at the following explanation: "Metadiscourse is the cover term for the self-reflective expressions used to negotiate interactional meanings in a text, assisting the writer (or speaker) to express a viewpoint and engage with readers as members of a particular community." This definition introduces a typology of the lexical items.

The most general classification of metadiscourse markers into interactive, also called textual (i.e., guiding the reader through the text), and interactional (i.e., involving the reader in the text) was also made by Hyland (1998a, 2004a, 2004b). Each of these two categories includes five types of metadiscourse markers with hedges and boosters (in other words, emphatics) belonging to the category of the interactional ones. Definitions of hedges and boosters have been widely discussed, for example, by Crompton (1997) and Hyland (1998b). For the purposes of this paper, the following definition of boosters, referring to their function, will be used: "[boosters] express conviction and assert a proposition with confidence, representing a strong claim about a state of affairs ... [they] mark involvement and solidarity with an audience, stressing shared information, group membership, and direct engagement with readers" (Hyland 1998b: 350). These are expressions, such as: of course, clearly, obviously, etc.

The definition of a hedge, which seems the most adequate, was formulated by Lyons (1977: 797; as cited by Crompton 1997: 281) in the following way: "an item of language which a speaker uses to explicitly qualify his/her lack of commitment to the truth of a proposition he/she utters." Examples of such expressions are: possible, might, perhaps, etc. Generally, hedges and boosters, which belong to the main interpersonal metadiscourse markers contribute to "the rhetorical expression of the relationship between writer and reader" (Hyland 2004b: 87). Used as communicative strategies, they increase (boosters) or reduce (hedges) the force of arguments. In other words, hedges are used to "move away from what can be safely assumed or experimentally demonstrated", and boosters 
to express "conviction or the significance of the work" (Hyland 2004b: 101). A convincing argument requires the use of both.

The occurrence of hedges and boosters in academic discourse written by Polish authors has not been explored extensively so far. Thus, the aim of this paper is to present a cross-linguistic and cross-cultural study comparing the use of these lexical items in the corpora of 20 research articles written by native English speakers, and in 20 articles written by Polish writers, specialists in the area of applied linguistics. It includes both quantitative and qualitative analyses of their appearance in the text. In the quantitative exploration, a chi-square test was conducted in order to compare the number of hedges and boosters in the corpora, and to establish whether the differences were statistically significant. It is argued here that the discrepancies between the usage of hedges and boosters by the two groups of writers may be linked with the national cultures that they represent. Before reporting on the results of the analyses carried out for the present paper, however, previous research results will be outlined below.

\section{Previous research}

The most extensive research on English metadiscourse, including hedges and boosters, has been carried out by the same author as cited above, i.e. Hyland (1998a, 1998b, 1999, 2004a, 2004b, 2005b, 2010), and by Hyland and Tse (2004). Most of the studies included analyses of disciplinary differences in the use of these lexical items in various genres. Many of them were also based on interviews with the writers of the texts (Hyland 1998b, 2004a, 2004b, 2005b, 2010). There are also cross-linguistic and cross-cultural studies by other authors outlined below. This review focuses on studies exploring genres such as research article, scientific letter ${ }^{1}$, academic textbook and dissertation. What they have in common is that they are usually antecedents and serve as models to be followed by novice scholars writing their first research articles.

In one of the studies published in 1998, Hyland analyzed 28 research articles written in English as a mother tongue in the following disciplines: microbiology, marketing, astrophysics and applied linguistics (Hyland 1998a). He found that there were $20 \%$ more metadiscourse markers, hedges in particular, in marketing than in any other disciplines. Also, in applied linguistics there were more interactional metadiscourse markers found. It was concluded that hedges play an important role in research writing, especially in the humanities and social sciences. Similar results Hyland (1998b) obtained in another study which was an

Scientific letter (also called 'squib' or 'quick report') is a very popular genre, especially in disciplines such as physics, chemistry or microbiology. It is usually less than four pages long, published monthly or weekly. Its aim is to announce new breakthroughs so it should be written in an understandable way to both researchers in the same and in other fields (Hyland 2004a). 
analysis of 56 research articles in mechanical engineering, electrical engineering, marketing, philosophy, sociology, applied linguistics, physics and microbiology. The focus of this exploration were only hedges and boosters. Thus, there were four times more hedges and boosters found in philosophy than in physics. In the whole corpus there were three times more hedges than boosters. The most frequently occurring ones were: may, would, and possible. Over $70 \%$ of hedges occurred in the humanities and social sciences. Interestingly, the largest number of boosters was in philosophy and the least (less than 7\%) in electrical engineering. In both studies, hedges were the most frequent metadiscourse markers in the whole corpus, which points to the writers' need to present claims with caution and deference to the views of the audience.

Hyland's 1999 study compared the use of metadiscourse markers in 21 textbook extracts and a similar corpus of research articles in the following disciplines: microbiology, marketing and applied linguistics. He found that in textbooks one-third of all metadiscourse markers were interactional, while in research articles, they constituted a half of them. As in the study mentioned above, their number was especially large in research articles in the area of marketing and applied linguistics. Moreover, three times more hedges were found in research articles than in textbooks. This seems logical as textbook writers most often present established knowledge to the readers, rather than cautiously introduce their new claims. Thus, the author points to the limitations of using only textbook extracts to teach research writing where metadiscourse knowledge is crucial.

In his book from 2004, Hyland also explored the use of metadiscourse markers in 56 textbook chapters in the following eight disciplines: philosophy, sociology, applied linguistics, marketing, electronic engineering, mechanical engineering, physics and biology (Hyland 2004a). Generally, epistemic markers (i.e., hedges and boosters) comprised half of all interactional discourse markers in the corpus, which points to the conclusion that the textbook content "is not simply an unreflecting repetition of uncontested disciplinary facts. Writers obviously have something to say on the epistemological status of what they report." (Hyland 2004a: 114). Hyland (2004a) found that texts from the 'soft' knowledge disciplines (the social sciences and humanities) included more interactional forms than texts from sciences. In the analyzed corpus, there was a smaller proportion of hedges in physics and engineering, and bigger proportion of boosters in engineering. In another study by Hyland (2005b), in which 240 research articles from the same eight disciplines were analyzed, similarly, more hedges were found in the 'soft' disciplines.

In the same publication, the use of hedges and boosters in 90 scientific letters from letters journals was explored by the author (Hyland 2004a). They were in the area of biology, chemistry and physics. Hyland (2004a) found that there was little difference between the disciplines in the occurrence of hedges and boosters in the letters. Hedges constituted about two-thirds of all such expressions in each field of science. However, there was around $50 \%$ more boosters in the scientific letters 
than in the research articles analyzed earlier by the same author, especially in the introductions and conclusions, which points to the strong need to promote the findings published in these venues.

Due to the fact that hedges usually constitute the largest proportion of interactional metadiscourse markers, their use alone in texts from various disciplines was also extensively researched at the end of the 1990s (e.g., Hyland 1996, in molecular biology; Varttala 1999, in medicine). Hyland (1998c) again was the author of the most comprehensive, in-depth descriptions of their occurrences in academic discourse. However, a review of the main arguments and research results included in this book goes beyond the scope of this article. Other lines of research need to be outlined here, because of their immediate relevance to the study carried out for the purposes of this paper, i.e. the analyses focusing on the use of hedges and boosters by writers in English as a second language, crosscultural comparisons of the use of these devices by native and non-native speakers of English, and by native speakers of different languages writing in their mother tongues.

Accordingly, in a series of studies, Hyland (2004b, 2010) and Hyland and Tse, (2004) have analyzed 240 doctoral and masters dissertations written by English as a second language (ESL) Chinese students from universities in Hong Kong. The dissertations were in the following six disciplines: electronic engineering, computer science, business studies, biology, applied linguistics and public administration. Generally, more metadiscourse markers were found in doctoral dissertations. The majority of devices found in the whole corpus were interactional. Hedges were the most common $(41 \%$ of all interactional metadiscourse) with modal verbs such as may, could, and would appearing with the highest frequency. There were $60 \%$ more of interactional metadiscourse markers, hedges in particular, in the 'soft' disciplines, i.e. business studies, public administration, and applied linguistics. The results point to the fact that students seem to be aware of the need to present their claims to supervisors and examiners in persuasive and acceptable ways (see also: Hyland 2005b).

More recently, a study comparing the use of hedges and boosters in research articles written in English as a foreign language (EFL) by Iranian and by AngloAmerican writers was carried out by Abdollahzadeh (2011). He focused on 60 conclusion sections of research articles in applied linguistics and found that the texts written by Anglo-American writers generally use more metadiscourse markers. Both groups of writers used an equal proportion of hedges but AngloAmerican writers employed more boosters in their writing. These markers also performed slightly different functions in the texts of the two groups of writers. The author ascribed the differences to the writers' varied rhetorical sensitivity and awareness of the audience.

Finally, two other cross-cultural and cross-linguistic studies comparing the use of hedges and boosters in research articles written in English and in Chinese are worth mentioning. In the first one by $\mathrm{Hu}$ and Cao (2011), 195 research article 
abstracts were analyzed. The corpus comprised three sub-corpora: Chinese abstracts published in Chinese-medium journals, abstracts in English published in Chinese-medium journals, and English abstracts in English-medium journals. The main results showed that more hedges appeared in the article abstracts in Englishmedium journals. The other two sub-corpora did not differ significantly in this respect. Also, there were more occurrences of boosters in the Chinese abstracts, published in Chinese-medium journals than in the other two sub-corpora. The latter did not differ in this respect. Thus, the English writers' arguments seemed more cautious, and the Chinese - more self-confident. The authors also compared the use of these devices in the abstracts of empirical and non-empirical academic articles (i.e., review, theoretical, methodological articles, etc.) and found that there were more occurrences of boosters in the former. The researchers claimed that the results can be ascribed to the cultural differences in the use of rhetorical strategies by the two groups of writers. In the second study, carried out by Mu, Zhang, Ehrich and Hong (2015), the authors compared the use of metadiscourse markers in 20 research articles in Chinese, and 20 in English. They were all from applied linguistics journals. The results showed that significantly more interactional metadiscourse markers appeared in the English sub-corpus than in the Chinese one. Hedges appeared most frequently in both sub-corpora. Similarly to the case in the previously described study, hedges occurred more often in English research articles. Chinese writers, on the other hand, employed more boosters. The two groups of writers also used hedges and boosters for slightly different purposes. As in the abovementioned study, the authors explained the results with the differences in cultural writing conventions followed by the writers.

From the above overview of the studies one can conclude that there are clear differences between texts in sciences, on the one hand, and the humanities and social sciences, on the other, in the use of hedges and boosters by native English speakers and ESL writers in many genres, except for scientific letters where the differences across disciplines were not significant. Moreover, in the studies comparing the use of hedges and boosters in research articles written by native English speakers and EFL writers, more differences were found when the scholars wrote in their mother tongues.

Few studies comparing Polish and Anglo-American research writing have been carried out, especially focusing on hedges and boosters. Apart from the research started in the 1990s by Duszak (1994) and Golebiowski (1998), the differences in cultural conventions followed by Polish and Anglo-American writers received scant attention so far (for an overview, see e.g., Hryniuk 2017). However, the abovementioned authors already noted that in the case of EFL writers, differences linked with the national cultures that they represent may play a crucial role. As Hyland and Milton (1997: 186) also observed, "students from different cultures may have preconceptions about the formal features of culturally and rhetorically appropriate writing which may differ from those which operate in English academic settings." Being educated in other cultures, novice writers may have a 
different sense of the audience and the writer. The main factor having impact on the cultural differences explored in this paper may be the fact that Polish academic writing is reader-responsible as opposed to Anglo-American one, which takes into consideration the audience (Duszak 1994). Thus, a Polish writer may not feel responsible for guiding the reader through the text or engaging him in the argument by using hedges and boosters.

One of the few more recent comparative studies on Polish and AngloAmerican research writing in medicine was Donesch-Jeżo's (2011) analysis of metadiscourse use. She analyzed 30 research articles and concluded that the factor which is expected to influence the use of boosters by Polish writers is academic modesty, highly valued in Polish culture. It does not allow them to describe their own work as interesting or useful. It is the reader who should make such judgments rather than the writer (Donesch-Jeżo 2011). Anglo-American writing, on the other hand, is characterized as more assertive and direct (Duszak 1994). More extensive research on epistemic modality markers used by the two groups of writers in 400 research articles in linguistics was also carried out by Warchat (2015). The results showed that Anglo-American writers used the markers of certainty and doubt twice more frequently, and boosters almost three times more frequently. Also, more of them could be found in the final sections of the articles. It must be noted, however, that both Donesch-Jeżo (2011) and Warchał (2015) compared texts written in English by Anglo-American writers with texts written in Polish by Polish writers. In the present study, all analyzed texts were written in English, so the outcome of the analyses described in the following section may be different.

\section{The study}

This study quantitatively and qualitatively investigates the differences and similarities in the use of hedges and boosters in the corpora of 40 research articles in the area of applied linguistics - 20 written by native English speakers, and 20 by Polish writers. All of the articles were in English. The aim of this study is to compare the frequency of their use and the location of hedges and boosters in particular sections of the IMRD structure (i.e., Introduction-Method-ResultsDiscussion) of research articles, and to explore if there are any significant differences in the types of hedges and boosters used in the two sub-corpora.

Thus, the study addresses the following research questions:

1. Are hedges and boosters used with the same frequency in the research articles written by Polish and Anglo-American writers?

2. Are there any significant differences in the distribution of hedges and boosters in particular sections of the $\operatorname{IMRD}(\mathrm{C})$ structure in the two subcorpora? 
3. Are there any significant differences in the types of hedges and boosters most frequently used by Polish and Anglo-American writers?

The study results will have implications for writing instruction in EFL aiming to develop sociolinguistic competence and expertise in writing. It involves raising awareness of different rhetorical conventions and the knowledge of the rhetorical effects that specific language resources can have on readers. Such instruction should assist novice writers in joining the target discourse community of experts.

\subsection{Corpus and methodology}

In order to address the research questions, the same corpus of 40 research articles was used as in my previous studies (see: Hryniuk 2015, 2016, 2017). It consisted of 20 research articles written by Polish writers, and 20 by native English speakers. The former set of articles was collected from two English-medium journals published in Poland, and the latter from two international journals published in the U.S. The main criteria for their selection were the following: they were all written in English; they were all from the area of applied linguistics; and they were all published in representative, peer-reviewed, highly reputable journals in the years 2009-2013. The equivalence of the sub-corpora content, also called tertium comparationis (Krzeszowski 1990), was achieved by using these criteria, in order to make meaningful comparisons, that is to compare the elements which can be compared and draw valid conclusions. One aspect in which the two subcorpora differed considerably was that the Anglo-American sub-corpus consisted of 191,423 words and the Polish one of 135,358. Consequently, the articles in the Anglo-American sub-corpus were on average by 2,800 words longer. However, according to the accepted methodology, in the analyses of such small specialized corpora full texts should be used (Bowker and Pearson 2002; Flowerdew 2004). Therefore, the number of the hedges and boosters occurrence per 1,000 words (i.e., the frequency of use) was counted as well.

All articles in the corpus had the IMRD structure, typical of articles in the experimental sciences, with each section performing different communicative function. The conclusion section was added because it was present in $95 \%$ of the Polish sub-corpus. The IMRD structure is prescribed in the American Psychological Association style manual (APA 2010) and two journals from which the articles were selected referred to this style manual directly. However, it must be noted that, unlike in sciences, in applied linguistics this structure is not always strictly followed. As for example Abdollahzadeh (2011: 291) noticed in his corpus of articles in applied linguistics, "most of the articles have conclusions, some others discussion sections, yet some had results and discussion merged." Similarly, in the present study in $40 \%$ of the articles of the Polish sub-corpus the discussion sections were merged with the preceding ones or they were missing, and in $40 \%$ of the Anglo-American sub-corpus, the same happened with the conclusion sections. 
In the present analyses, the taxonomy of metadiscourse markers, including hedges and boosters, introduced by Hyland (2004a, 2005a) was used. The list of hedges consisted of modal auxiliaries (e.g. would, might, could), epistemic adjectives and adverbs (e.g. perhaps, mainly, likely), epistemic lexical verbs (e.g. seem, suggest, assume), and other (e.g. assumption (that), In general). The list of boosters was comprised of modal auxiliaries (e.g. must to express possibility, will), epistemic lexical verbs (e.g. demonstrate, find, show), epistemic adjectives and adverbs (e.g. actually, always, clearly) and other (e.g. it is well known (that), the fact that) ( $\mathrm{Hu}$ and $\mathrm{Cao}$ 2011: 2800). The complete list of 180 lexical expressions can be found in Hyland (2004a: 188-189). This compilation is based on much literature and research so it is the most reliable and appropriate for the purposes of this study.

In order to arrive at an in-depth insight into the use of hedges and boosters, and to achieve precision, in the present analysis a concordance program WordSmith Tools 6.0 (Scott 2012) was utilized. Concordance lines were generated and hedges and boosters were analyzed in context. First of all, the examples of hedges and boosters which were used in the utterances expressed by the writers' informants, rather than by the writers themselves, were excluded. The importance of context must be emphasized in this analysis because the distinction has to made between propositional and epistemic meaning of the expressions. For instance, in the sentence number (1) below, the word about functions as a hedge (i.e. approximation) indicating that the number is accurate enough in this text.

(1) There were about 300 punctuation marks in this text.

(2) Many authors write about the importance of the quality of the input.

In the example sentence number (2), the preposition about is only employed for signaling the proposition which follows; it is not a hedge (i.e., approximation).

Also, it must be noted that the same word can function both as a hedge and as a booster, depending on the context. For example, the word quite can perform a function of a hedge (e.g. quite good) or a booster (e.g. quite remarkable) (Hyland and Milton 1997). Thus, because of highly contextual nature of metadiscourse, all instances of hedges and boosters were individually, carefully analyzed in their sentential context first by the researcher to determine their actual functions. Then, the second rater analyzed the disputable cases till the satisfactory agreement of approximately $89 \%$ was reached. Finally, a chi-square analysis was undertaken to determine whether there are statistically significant differences between the number of hedges and boosters in the sub-corpora.

\subsection{Results}

Table 1 shows that even though the total number of boosters is larger in the AngloAmerican sub-corpus than in the Polish one, the frequency of their use per 1,000 words is almost the same. When we take into consideration hedges, the number of 
them in the Anglo-American sub-corpus is also larger. However, if we take into account the frequency, one can clearly see that it is higher in the Polish sub-corpus and the difference is statistically significant. 
Table 1. The number and the frequency of hedges and boosters use per 1,000 words in each sub-corpus in the brackets. Last column - chi-square test results.

\begin{tabular}{|l|l|l|l|}
\hline & Am. & Polish & $\boldsymbol{\chi}^{\mathbf{2}}(\mathbf{P})$ \\
\hline Boosters & $1075(5.6)$ & $767(5.7)$ & $0.004(0.843)$ \\
\hline Hedges & $2303(12.0)$ & $1980(14.6)$ & $39.48\left(<0.001^{*}\right)$ \\
\hline
\end{tabular}

*statistically significant difference between the Anglo-American and the Polish subcorpora.

When we look at the numbers and frequency of hedges and boosters used in particular sections of the IMRD structure (Table 2), we can see that in most of the sections of the IMRD structure there are more both hedges and boosters in the Anglo-American corpus, but there are a few exceptions. As far as the number of boosters in the results sections is concerned, in the Anglo-American sub-corpus it is larger, but the frequency of their use per 1,000 words is higher in the Polish sub-corpus, and the difference is statistically significant. The frequency of boosters use in the discussion sections in the Polish sub-corpus is also slightly larger than in the Anglo-American one, but the difference is not statistically significant. In the conclusion sections, both the total number and the frequency of boosters use is much larger in the Polish sub-corpus and the difference is statistically significant.

As far as the use of hedges is concerned, both their total number and the frequency of use per 1,000 words is larger in the results sections of the Polish subcorpus than in the Anglo-American one, and the difference is statistically significant. Although in the discussion sections the number of hedges is bigger in the Anglo-American sub-corpus, the frequency of their use is larger in the Polish sub-corpus. However, the difference is not statistically significant. Finally, in the conclusion sections the number and the frequency of hedges use is much larger in the Polish sub-corpus and the difference is statistically significant.

Table 2. The number and the frequency of hedges and boosters use in particular sections of the articles, and chi-square test results.

\begin{tabular}{|l|l|l|l|l|}
\hline Markers & \multirow{2}{*}{ Corpus } & \multicolumn{3}{|c|}{ Article section } \\
\cline { 3 - 5 } & & Introduction & Method & Results \\
\hline \multirow{3}{*}{ Boosters } & Ang.-Am. & $328(5.5)$ & $194(4.6)$ & $239(4.9)$ \\
\cline { 2 - 5 } & Polish & $257(4.8)$ & $101(4.3)$ & $215(5.9)$ \\
\cline { 2 - 5 } & $\chi^{\mathbf{2}}(\mathbf{P})$ & $2.94(0.086)$ & $0.36(0.549)$ & $4.45\left(0.035^{*}\right)$ \\
\hline \multirow{3}{*}{ Hedges } & Ang.-Am. & $747(12.5)$ & $404(9.6)$ & $394(8.0)$ \\
\cline { 2 - 5 } & Polish & $723(13.6)$ & $235(9.9)$ & $517(14.2)$ \\
\cline { 2 - 5 } & $\chi^{\mathbf{2}}(\mathbf{P})$ & $1.77(0.184)$ & $0.21(0.646)$ & $76.8\left(<0.001^{*}\right)$ \\
\hline
\end{tabular}




\begin{tabular}{|l|l|l|l|l|}
\hline Markers & Corpus & \multicolumn{3}{|c|}{ Article section } \\
\hline & & Discussion & Conclusion & \\
\hline \multirow{3}{*}{ Boosters } & Ang.-Am. & $294(8.2)$ & $20(4.3)$ & \\
\cline { 2 - 5 } & Polish & $96(8.6)$ & $98(9.5)$ & \\
\cline { 2 - 5 } & $\chi^{\mathbf{2}}(\mathbf{P})$ & $0.15(0.703)$ & $11.24\left(<0.001^{*}\right)$ & \\
\hline \multirow{3}{*}{ Hedges } & Ang.-Am. & $723(20.2)$ & $35(7.5)$ & \\
\cline { 2 - 6 } & Polish & $250(22.4)$ & $246(23.8)$ & \\
\cline { 2 - 6 } & $\chi^{\mathbf{2}}(\mathbf{P})$ & $1.97(0.160)$ & $46.84\left(<0.001^{*}\right)$ & \\
\hline
\end{tabular}

*statistically significant difference between the Anglo-American and the Polish subcorpora.

Many differences between the sub-corpora can also be noticed when we look at the types of the metadiscourse markers used. In the tables below we can see what types of hedges and boosters appeared in the two sub-corpora in particular article sections in the highest number, i.e. on the first place, on the second and on the third place. The numbers of their occurrences are given next to the expressions. Those which were generally the most numerous in the whole sub-corpus, notwithstanding the section, are in bold type, and those which were on the second place are underlined.

Table 3. The types of boosters appearing in the largest numbers in the Polish sub-corpus.

\begin{tabular}{|c|l|l|l|l|l|}
\hline & Introduction & Method & Results & Discussion & Conclusion \\
\hline 1. & particularly & at least & the fact that & must, the fact that & the fact that \\
& 23 & 8 & 27 & 9 & 12 \\
\hline 2. & the fact that & establish & show & clearly & will \\
& 22 & 7 & 20 & 7 & 11 \\
\hline 3. & $\begin{array}{c}\text { indeed } \\
18\end{array}$ & $\begin{array}{c}\text { show } \\
\end{array}$ & $\begin{array}{c}\text { particularly, will } \\
16\end{array}$ & $\begin{array}{c}\text { indeed, show, will } \\
5\end{array}$ & must \\
\end{tabular}

Table 4. The types of boosters appearing in the largest numbers in the Anglo-American sub-corpus.

\begin{tabular}{|c|c|c|c|c|c|}
\hline & Introduction & Method & Results & Discussion & Conclusion \\
\hline 1. & $\begin{array}{ll}\text { will } & \\
49\end{array}$ & $\begin{array}{l}\text { will } \\
59\end{array}$ & $\begin{array}{ll}\text { will } & \\
& 23\end{array}$ & $\begin{array}{ll}\text { will } & \\
& 26\end{array}$ & $\begin{array}{ll}\text { clearly } & \\
5\end{array}$ \\
\hline 2. & $\frac{\text { determine }}{30}$ & $\begin{array}{r}\text { at least } \\
22 \\
\end{array}$ & $\begin{array}{l}\text { given that, at least } \\
18\end{array}$ & $\begin{array}{r}\text { evidence } \\
22 \\
\end{array}$ & at least \\
\hline 3. & $\begin{array}{c}\text { evidence } \\
23 \\
\end{array}$ & $\begin{array}{r}\text { must } \\
21 \\
\end{array}$ & show & $\frac{\text { determine }}{17}$ & $\begin{array}{c}\text { necessarily, quite } \\
2\end{array}$ \\
\hline
\end{tabular}

As far as boosters are concerned, Polish writers used the fact that most often in almost all article sections, except for the method section, and the second most frequently appearing word was the adverb particularly (see Table 3). AngloAmerican writers used will most frequently in almost all article sections, except for the conclusion, and the second most often used item was the lexical verb determine (see Table 4). 
Table 5. The types of hedges occurring in the largest numbers in the Polish sub-corpus.

\begin{tabular}{|c|c|c|c|c|c|}
\hline & Introduction & Method & Results & Discussion & Conclusion \\
\hline 1. & $\begin{array}{ll}\text { may } & \\
& 169\end{array}$ & $\begin{array}{ll}\text { may } & \\
& \end{array}$ & $\begin{array}{ll}\text { may } & \\
& 65\end{array}$ & $\begin{array}{ll}\text { may } & \\
& \end{array} 2$ & $\underbrace{\text { should }}_{38}$ \\
\hline 2. & $\begin{array}{ll}\text { often } & \\
& 37 \\
\end{array}$ & $\begin{array}{r}\text { would } \\
18 \\
\end{array}$ & $\begin{array}{l}\text { might } \\
36\end{array}$ & $\underline{\text { might }}_{19}$ & may \\
\hline 3. & $\underline{\text { should }}_{32}$ & $\begin{array}{l}\text { could } \\
16\end{array}$ & $\begin{array}{r}\text { rather } \\
28\end{array}$ & $\stackrel{\text { should }}{15}_{15}$ & $\underline{\text { might }}_{30}$ \\
\hline
\end{tabular}

Table 6. The types of hedges occurring in the largest numbers in the Anglo-American sub-corpus.

\begin{tabular}{|c|c|c|c|c|c|}
\hline & Introduction & Method & Results & Discussion & Conclusion \\
\hline 1. & may $_{138}$ & $\frac{\text { would }}{60}$ & $\frac{\text { would }}{42}$ & $\operatorname{may}_{115}$ & $\begin{array}{ll}\text { would } & \\
\end{array}$ \\
\hline 2. & $\begin{array}{l}\text { rather } \\
55\end{array}$ & $\begin{array}{l}\text { could } \\
32\end{array}$ & $\begin{array}{r}\text { may } \\
34\end{array}$ & $\frac{\text { would }}{70}$ & $\begin{array}{l}\text { could, may, suggest } \\
3\end{array}$ \\
\hline 3. & $\begin{array}{l}\text { often } \\
45\end{array}$ & $\begin{array}{c}\text { may, possible } \\
25\end{array}$ & $\begin{array}{r}\text { rather } \\
27\end{array}$ & $\begin{array}{l}\text { could } \\
65\end{array}$ & possible, quite, seem \\
\hline
\end{tabular}

With regard to hedges, there is no difference in the type of most frequently used word between the sub-corpora (see Table 5 and 6). The modal verb may was the most often occurring hedge in both the Polish and the Anglo-American subcorpus. However, while in the articles written by Polish writers modal verbs mainly performed the function of hedges, in those written by Anglo-American writers more variety was noticed. There were also epistemic adjectives and adverbs and epistemic lexical verbs used more frequently.

\section{Discussion}

The results of the study are quite unexpected. The quantitative analyses of the texts mainly show that, overall, Polish writers used more hedges than AngloAmerican ones, which is contrary to what was found in the research by Warchał (2015). However, as it was mentioned in section 2. of this paper, Warchał (2015) compared the use of epistemic modality markers by Polish writers writing in Polish with Anglo-American writers writing in English. In this study, all articles were written in English, which may explain the differences in the outcomes. The larger number of hedges in the Polish sub-corpus can be the result of cultural differences in writing. It may be the consequence of following the accepted ways of expression in Polish writing, exhibiting academic modesty, but not as predicted by Donesch-Jeżo (2011) by avoiding the use of boosters, but by using larger amount of hedges. This makes their writing more tentative, less assertive and indirect as compared with Anglo-American style of writing (Duszak 1994).

Another outcome of the present study is that higher concentration of both hedges and boosters was found in the results and the conclusion sections of the 
Polish sub-corpus. Warchał (2015) also showed in her research that more epistemic modality markers can be located in the final sections of articles, which seems logical as these are discussions and the conclusion sections where writers usually try to introduce their new claims and guide readers through the arguments based on results of their studies. Larger concentration of hedges and boosters in the results sections of the Polish sub-corpus may be explained with the fact that Polish writers tend to merge the discussion with the results sections, which was the case in $40 \%$ of articles from the Polish sub-corpus, and begin to shape their argument already in the results sections. Also, higher frequency of metadiscourse markers in the conclusion sections of the Polish sub-corpus may be due to the fact that this section was present in all but one article there, while in $40 \%$ of the AngloAmerican sub-corpus it was not distinguished. It was merged with the discussion section or missing. Thus, because writers in applied linguistics do not always follow strictly the conventional IMRD $(C)$ structure of research article, the content of particular sections of articles is often shifted both in writing by Polish writers (from the discussion to the results sections) and by the Anglo-American writers (from the conclusion to the discussion sections), and so is the concentration of hedges and boosters in particular article sections (see also: Hryniuk 2017).

The differences in the types of hedges and especially boosters used by Polish and Anglo-American writers were also noticed in the qualitative analyses in the present study. The most frequently appearing lexical items performing the function of boosters in the Polish sub-corpus were the fact that and particularly. This may be the result of transfer from the mother tongue, as the same words and phrases are also very frequently used in Polish. Moreover, they do not seem to express as much confidence as the words will and determine, used most frequently by the Anglo-American writers in the present study. Employing the former ones in combination with hedges in the co-text allows Polish writers to preserve the overall impression of being more tentative and modest, and to follow their culturally shaped ways of expression in this way, even though in Anglo-American culture it may be regarded as a sign of weakness. Finally, as far as hedges are concerned, Anglo-American writers, by definition more linguistically skilled, tended to use more variety of hedging devices than Polish writers. It seems that this characteristic feature of native-speaker competence should be more often focused on in EFL writing instruction (see also: Hryniuk 2015).

A few limitations of the study must be also acknowledged. First of all, the study results cannot be generalized to all research writing by Anglo-American and Polish writers, as the number of articles analyzed was not very large. Also, it must be admitted that some of the abovementioned explanations may be regarded as speculations. Further research would benefit from explorations of a larger corpora and more qualitative analyses of how writers use hedges and boosters in context, as well as from interviews with writers about the reasons behind the use of specific rhetorical devices and about their perceptions. 


\section{Conclusions}

Summing up, it must be stated that the results of the present study do not completely support previous research. They indicate that the differences between the use of metadiscourse markers by writers representing different cultures exist, but more research is needed in this area in order to arrive at clearer explanations of the differences and accurate interpretations of research results. We need to acknowledge that native culture conventions are not the only factors influencing written communication. The use of hedges and boosters may also be impacted by individual factors, such as self-confidence and experience of writers. Their use depends on context as well. Moreover, it is often regarded as unreflective and automatic. Thus, more research findings would contribute both to the development of knowledge in this area and to the improvement in EFL writing instruction.

It seems that improvements in EFL writing instruction based on more research in this area are very much needed. Writers representing other than AngloAmerican cultures, trying to publish in anglophone journals, would benefit from the instruction focused on specific metadiscourse markers, not only to increase or decrease their amount in their writing, but also to learn how to use them in context in order to achieve the desired rhetorical effects. Explorations of corpora, as it was done in the present study, by applying corpus linguistics tools and DDL on academic writing courses, would lead to raising EFL writers awareness of the effective rhetorical strategies which they can use depending on the audience. It would be conductive to developing expertise in writing by EFL scholars as well. Finally, publication gatekeepers - editors and reviewers - would benefit from more research in this area, and the recognition that the same texts can be perceived differently by culturally diverse audiences. But first and foremost, what we all need is better understanding of how complex combinations of cultural and individual factors influence writing.

\section{References}

Abdollahzadeh, Esmaeel. 2011. Poring over the Findings. Interpersonal Authorial Engagement in Applied Linguistics Papers. Journal of Pragmatics 43. 288-297.

American Psychological Association. 2010. Publication Manual of the American Psychological Association (6th ed.). Washington DC: Author.

Ädel, Annelie. 2006. Metadiscourse in L1 and L2 English. Amsterdam: John Benjamins.

Bowker, Lynne and Jennifer Pearson. 2002. Working with Specialized Language: A Practical Guide to Using Corpora. London: Routledge.

Crompton, Peter. 1997. Hedging in Academic Writing: Some Theoretical Problems. English for Specific Purposes 16(4). 271-287.

Cumming, Alister. 1989. Writing Expertise and Second-Language Proficiency. Language Learning 39(1). 81-141. 
Donesch-Jeżo, Ewa. 2011. Comparison of Generic Organization of the Research Paper in English and Polish: Cross-Cultural Variation and Pedagogical Implications. Journalism and Mass Communication 1(3). 185-200.

Duff, Patricia A. 2007. Problematising Academic Discourse Socialisation. In: Helen Marriott, Tim Moore and Robyn Spence-Brown (eds.), Learning Discourses and the Discourses of Learning, 1-18. Melbourne: Monash University Press.

Duff, Patricia A. 2010. Language Socialization into Academic Discourse Communities. Annual Review of Applied Linguistics 30. 169-192.

Duszak, Anna. 1994. Academic Discourse and Intellectual Styles. Journal of Pragmatics 21. 291313.

Flowerdew, John. 2013. English for Research Publication Purposes. In: Brian Paltridge and Sue Starfield (eds.), The Handbook of English for Specific Purposes, 301-321. Chichester: WileyBlackwell.

Flowerdew, Lynne. 2004. The Argument for Using English Specialized Corpora to Understand Academic and Professional Language. In: Ulla Connor and Thomas Upton (eds.), Discourse in the Professions: Perspectives from Corpus Linguistics, 11-33. Amsterdam: John Benjamins.

Golebiowski, Zofia. 1998. Rhetorical Approaches to Scientific Writing: An English-Polish Contrastive Study. Text 18(1). 87-102.

Hryniuk, Katarzyna. 2015. Metalinguistic Expressions in Research Articles Written by Polish and English Native-Speakers: A Corpus-Based Study. In: Anna Turula and Maria Chojnacka (eds.), CALL for Bridges in School and Academia, 33-47. Berno: Peter Lang.

Hryniuk, Katarzyna. 2016. The Use of Citations in Research Articles Written by Polish and English Native-Speaker Writers. In: Halina Chodkiewicz, Piotr Steinbrich and Małgorzata KrzemińskaAdamek (eds.), Working with Text and Around Text in Foreign Language Environments, $143-$ 157. Heidelberg: Springer.

Hryniuk, Katarzyna. 2017. Linguistics Research Articles Written in English: Comparing Native English Speakers and Polish Writers. International Journal of Applied Linguistics 27(1). 3-23.

$\mathrm{Hu}$, Guangwei and Feng Cao. 2011. Hedging and Boosting in Abstracts of Applied Linguistics Articles: A Comparative Study of English- and Chinese-Medium Journals. Journal of Pragmatics 43. 2795-2809.

Hyland, Ken. 1996. Writing Without Conviction? Hedging in Science Research Articles. Applied Linguistics 17(4). 433-454.

Hyland, Ken. 1998a. Persuasion and Context: The Pragmatics of Academic Discourse. Journal of Pragmatics 30. 437-455.

Hyland, Ken. 1998b. Boosting, Hedging and the Negotiation of Academic Knowledge. Text 18(3). 349-382.

Hyland, Ken. 1998c. Hedging in Scientific Research Articles. Amsterdam: John Benjamins.

Hyland, Ken. 1999. Talking to Students: Metadiscourse in Introductory Coursebooks. English for Specific Purposes 18(1). 3-26.

Hyland, Ken. 2004a. Disciplinary Discourses: Social Interactions in Academic Writing. Ann Arbor, Mich.: University of Michigan Press.

Hyland, Ken. 2004b. Disciplinary Interactions: Metadiscourse in L2 Postgraduate Writing. Journal of Second Language Writing 13(2). 133-151.

Hyland, Ken. 2005a. Metadiscourse: Exploring Interaction in Writing. London: Continuum.

Hyland, Ken. 2005b. Stance and Engagement: A Model of Interaction in Academic Discourse. Discourse Studies 7(2). 173-192.

Hyland, Ken. 2009. English for Professional Academic Purposes: Writing for Scholarly Publication. In Diane Belcher (ed.), English for Specific Purposes in Theory and Practice, 83-105. Ann Arbor: The University of Michigan Press.

Hyland, Ken. 2010. Metadiscourse: Mapping Interactions in Academic Writing. Nordic Journal of English Studies 9(2). 125-143. 
Hyland, Ken and John Milton. 1997. Qualification and Certainty in L1 and L2 Students' Writing. Journal of Second Language Writing 6(2). 183-205.

Hyland, Ken and Polly Tse. 2004. Metadiscourse in Academic Writing: A Reappraisal. Applied Linguistics 25(2). 156-177.

Johns, Tim. 1991. Should You Be Persuaded: Two Examples of Data-Driven Learning. Classroom Concordancing. English Language Research Journal 4. 1-16.

Krzeszowski, Tomasz P. 1990. Contrasting Languages: The Scope of Contrastive Linguistics. Berlin: Mouton de Gruyter.

Lyons, John. 1977. Semantics. Cambridge: Cambridge University Press.

$\mathrm{Mu}$, Congjun, Zhang, Lawrence Jun, Ehrich, John and Huaqing Hong. 2015. The Use of Metadiscourse for Knowledge Construction in Chinese and English Research Articles. Journal of English for Academic Purposes 20. 135-148.

Scott, Mike. 2012. WordSmith Tools (version 6.0). Liverpool: Lexical Analysis Software.

Varttala, Teppo. 1999. Remarks on the Communicative Functions of Hedging in Popular Scientific and Specialist Research Articles on Medicine. English for Specific Purposes 18(2). 177-200.

Warchał, Krystyna. 2015. Certainty and Doubt in Academic Discourse: Epistemic Modality Markers in English and Polish Linguistics Articles. Katowice: Wydawnictwo Uniwersytetu Śląskiego.

Weigle, Sara C. 2005. Second Language Writing Expertise. In: Keith Johnson (ed.), Expertise in second language learning and teaching, 128-149. New York: Palgrave Macmillan. 